\title{
LOS RECURSOS MINEROS EN LAS CADENAS GLOBALES DE VALOR
}

\author{
Yuri Landa Arroyo ${ }^{a}$
}

Fecha de recepción: 18 de febrero de 2019. Fecha de aceptación: 10 de junio de 2019.

http://dx.doi.org/10.22201/iiec.20078951e.2019.199.68330

\begin{abstract}
Resumen. Este trabajo identifica a nivel industria-país las cadenas de valor en el mundo que hace uso intensivo de minerales, señala además qué empresas las lideran, y qué países han escalado su posición a mayor valor agregado. Las estimaciones se lograron mediante instrumentos propios del análisis insumo-producto complementado con algoritmos de la teoría de redes, teniendo como fuente de información las tablas de insumo-producto internacionales elaboradas por la OECD, con información de 33 sectores económicos de 63 países, para los años 1995 y 2011. La evidencia muestra casos de escalamiento hacia adelante del sector extractivo en Brunéi, Indonesia y Malasia hacia eslabones más sofisticados en las cadenas globales de valor (CGV).
\end{abstract}

Palabras clave: minería; cadenas globales de valor; industrialización; tablas insumoproducto; teoría de redes sociales; consumo mundial.

Clasificación JEL: F23; D57; L72; O14.

\section{Mining RESOURCES IN GLOBAL VALUE CHAINS}

Abstract. This article identifies at an industrial-national level which global value chains make intensive use of mining, demonstrating additionally which companies are leading this phenomenon and what countries have elevated their position to greater added value. Calculations were performed using input-out analysis methods, complemented by network theory algorithms, and were based on international input-output tables produced by the OECD which provide information for 33 economic sectors in 63 countries for the period from 1995 to 2011. The evidence shows escalating cases towards more sophisticated links in global value chains (GVC) in the extractive sectors of Brunei, Indonesia and Malaysia.

Key Words: mining; global value chains; industrialization; input-output tables; social network theory; world consumption.

\footnotetext{
${ }^{a}$ Universidad de Lima, Perú. Correo electrónico: ylanda@ulima.edu.pe
} 


\section{INTRODUCCIÓN}

Desde fines del siglo pasado, el comercio mundial alcanzó una nueva etapa en el proceso de división internacional del trabajo gracias a la formación de cadenas globales de valor (CGV) (Baldwin y Lopez-Gonzales, 2013), vislumbrando un escenario que hace posible nuevas oportunidades de industrialización para economías en desarrollo. Sin embargo, existe todavía un buen número de países cuya canasta exportadora se concentra en materias primas con poco valor agregado. Se considera importante identificar cuáles son las CGV en las que los recursos mineros tienen un peso dominante o estratégico; cuáles son los principales países proveedores de minerales; cuáles son las empresas que lideran los eslabones más importantes de la cadena, y evaluar los casos en los que un país ha podido dar el salto hacia un eslabón más sofisticado de esta cadena.

Gracias a bases de datos como Inter-Country Input-Output Tables de la Organización para la Cooperación y el Desarrollo Económicos (oECD, 2016) se pueden evaluar cambios en la estructura del comercio internacional a nivel de industria-país, identificar grados de fragmentación de la producción en una cadena específica, grados de interdependencia entre sectores y dónde se concentra el mayor valor agregado, tal como lo plantean Baldwin y LopezGonzales (2013), Los et al. (2015), Timmer et al. (2014), entre otros.

En el caso de la presente investigación, el análisis del rol de los recursos naturales en las CGV se hace a nivel de sector productivo y se utilizan herramientas propias del análisis insumo-producto, complementadas con algoritmos de la teoría de redes, inspirados en las publicaciones de García et al. (2008), Chai et al. (2011) y Noguera-Méndez et al. (2016).

El documento se organizó de la manera siguiente: se presenta primero el concepto encadenamientos en el marco de la teoría económica y en el enfoque de CGV; secundan las herramientas de cálculo propias del análisis insumoproducto tradicional y de la teoría de redes, para continuar con los resultados en cuanto a los países que han podido escalar a posiciones de mayor valor agregado a lo largo de la cadena. Se continúa con la descripción de las empresas que lideran estas CGV y, finalmente, se presentan las conclusiones.

\section{ENCADENAMIENTOS PRODUCTIVOS E INDUSTRIALIZACIÓN}

La división del trabajo y los respectivos encadenamientos de las tareas especializadas son dos procesos que cuando ocurren de manera simultánea tienen efectos favorables sobre la productividad. Estos han sido considerados como 
un rasgo implícito o explícito en los estudios de la industrialización. Kuznets (1974) muestra que, desde el inicio de la Revolución Industrial, la formación de un sector que ofrece bienes de capital fue una condición indispensable para el crecimiento del resto de manufacturas de bienes de consumo y bienes intermedios en Europa.

Entre estos sectores, los encadenamientos surgieron de manera bastante natural y en la actualidad son parte implícita de su fortaleza industrial, ya que las innovaciones de producto en las industrias de máquinas y herramientas se hacen hoy en día en vínculo estrecho con las manufacturas en cuyos procesos serán empleadas, afectando directamente su productividad y en muchos casos contagiando a los procesos de otros sectores vinculados (CECIMO, 2011).

Hirschman (1964) usando las tablas insumo-producto encuentra que los encadenamientos industriales hacia adelante y hacia atrás crean una fuerte interdependencia sectorial en las economías desarrolladas y se distinguen por eso de las economías en desarrollo. Este y otros autores -como Leontief (1966), Rasmussen (1956), Chenery y Watanabe (1958) - ofrecen diversos multiplicadores para evaluar los encadenamientos productivos, entre los que destaca el coeficiente de Leontief que será empleado en este trabajo.

Dados los procesos de industrialización en el mundo, en la segunda parte del siglo $\mathrm{xx}$, los encadenamientos cobran protagonismo en el espacio internacional. Rodrik (2011) considera que el crecimiento económico en varios países en desarrollo es resultado de la habilidad para integrarse con la economía mundial a través del comercio y la inversión. Esta idea es potenciada por Hausmann et al. (2007) quienes desarrollan un conjunto de indicadores bajo el concepto de que la forma en que una economía se encadena al mundo a través de sus exportaciones es uno de los determinantes de su crecimiento. Así, la canasta exportadora se convierte en una medida del grado de industrialización de un país, y un cambio sostenido en su composición implica haber logrado internamente una transformación estructural (Hausmann y Klinger, 2006), impulsada por los vínculos con los mercados externos.

A la división del trabajo y de los encadenamientos, ahora internacionales, los autores anteriores añaden los conceptos de diversificación y complejidad de la producción, en vista de que se trata de rasgos existentes en los países de desarrollo industrial reciente, en específico de varias economías asiáticas. Hidalgo y Hausmann (2009) señalan que países con mayores capacidades productivas son más diversificados, ya que pueden producir una mayor variedad de bienes. El tipo de bienes que exporta un país es un buen predictor de su ingreso per cápita.

La propuesta de la diversificación es importante pues contrasta con la especialización en exportación de bienes primarios existente en varios países 
dotados de abundantes recursos naturales, como es el caso de varias economías de Latinoamérica, Oriente Medio y África. Las bondades resultantes de este tipo de especialización se apoyan en la teoría de las ventajas comparativas de la económica clásica y han sido acompañadas por la propuesta liberal de los años ochenta conocida como el Consenso de Washington (Rodrik, 2011), aplicada en Latinoamérica en los años noventa, teniendo como fin el logro de los equilibrios macroeconómicos básicos, a saber, el fiscal, el externo y el monetario.

No obstante haber gozado de los equilibrios macroeconómicos buscados, la poca diversificación resultante, acompañada además de un retraso industrial, configura economías cuyo crecimiento depende en exceso de auges de precios externos de unas cuantas materias primas. La situación ha sido abordada, desde otra perspectiva, por la llamada "enfermedad holandesa" de Corden y Neary (1982), y por la "maldición de los recursos naturales" de Sachs y Warner (2001). De acuerdo con el enfoque de estos autores, es precisamente la abundancia de un recurso la que inhibe el crecimiento de otros sectores e inclusive reduce su productividad, fortaleciendo el sesgo concentrado de la canasta exportadora.

Finalmente, dados los encadenamientos que caracterizan en la actualidad a la producción transnacional, un enfoque adecuado para su estudio es el de las CGV, que se definen como el conjunto de unidades económicas que realizan las actividades necesarias para crear un producto o servicio, desde su concepción hasta la venta al usuario final. De acuerdo con Gereffi y Lee (2016), el enfoque se construye para entender cómo el valor agregado es creado y capturado dentro de varios tipos de industrias. Con ello ofrece un nivel de evaluación más detallado si se le compara con las teorías de crecimiento económico de fines de siglo pasado, en las que predomina el uso de herramientas macroeconómicas o a lo más sectoriales (Dussel, 2018).

El enfoque tiene como objeto de estudio empresas y grupos industriales específicos en el plano organizacional. Se centra en dos rasgos de la organización industrial vigente: la gobernanza y el escalamiento. La gobernanza estudia cómo la empresa líder organiza su cadena de suministro a escala global, mientras que el escalamiento identifica las estrategias utilizadas por empresas o países para mejorar sus posiciones en actividades con mayor valor agregado en la cadena (Gereffi y Lee, 2016).

En los métodos de gobernanza se identifica un amplio espectro de estrategias tales como la de mercado, basada en la adquisición recurrente de suministros simples a un mismo proveedor sin mayor coordinación explícita; la modular, que es cuando el proveedor produce suministros de características explícitas para la empresa líder, asumiendo los riesgos de las inversiones nece- 
sarias; la relacional, cuando por la complejidad del bien suministrado se crea una dependencia mutua entre ambas empresas; la cautiva, en la que pequeños proveedores son controlados y monitoreados por la empresa líder para el abastecimiento de un insumo, y la jerárquica, que se refiere a la instalación de una sucursal, bajo el control propietario, que provea el insumo requerido (Gereffi et al., 2005). En cuanto al escalamiento, Gereffi y Lee (2016) lo clasifican según el ámbito de la mejora, es decir, si se ha logrado un cambio en el producto, en el proceso productivo o se ha podido saltar a un eslabón superior de la cadena.

Partiendo del enfoque de CGV, Baldwin y Lopez-Gonzales (2013) desarrollan medidas de comercio de valor agregado, para identificar cómo ha cambiado su generación a través de los eslabones de la cadena. Estos autores, por un lado, y Timmer et al. (2014), por otro, constatan que las economías desarrolladas (dígase países del G7) se han convertido sobre todo en proveedoras de servicios, trasladando eslabones de manufactura a otros países (por ejemplo, China, México y Polonia), propiciando con ello su industrialización. Asimismo, Blyde (2014) sostiene la posibilidad de una industrialización rápida para el caso de países que facilitan el eslabonamiento de sectores nacionales en una CGV. Dicho de otro modo, en la medida en que los casos particulares de escalamiento dentro de una economía se acumulan, el resultado es un cambio en la estructura de producción que se reflejará en la composición de la canasta exportadora y otros indicadores de desarrollo industrial.

\section{DATOS Y MÉTODOS}

\section{Herramientas del análisis insumo-producto}

La medición de los encadenamientos se vincula a las tablas insumo-producto (тір) desarrolladas por Leontief. En el presente texto, los datos procesados provienen de las TIP internaciones para los años 1995 y 2011, publicadas por la OECD (2016), que contienen transacciones entre 33 sectores económicos de 63 países, en cuya denominación se usa la nomenclatura IsO3. ${ }^{1}$ La evaluación

1 ARG=Argentina; AUS=Australia; AUT=Austria; $\mathrm{BEL}=$ Bélgica; $\mathrm{BGR}=\mathrm{Bulgaria} ; \quad \mathrm{BRA}=\mathrm{Brasil}$; $\mathrm{BRN}=$ Brunéi; $\mathrm{CAN}=$ Canadá; $\mathrm{CHE}=$ Suiza; $\mathrm{CHL}=\mathrm{Chile} ; \mathrm{CHN}=\mathrm{China}$; $\mathrm{COL}=$ Colombia; $\mathrm{CRI}=\mathrm{Costa}$ Rica; $\mathrm{CYP}=$ Chipre; $\mathrm{CZE}=$ República Checa; $\mathrm{DEU}=$ Alemania; $\mathrm{DNK}=$ Dinamarca; ESP=España; EST=Estonia; FIN=Finlandia; FRA=Francia; GBR=Reino Unido; GRC=Grecia; HKG=Hong Kong; HRV=Croacia; HUN=Hungría; IDN=Indonesia; IND=India; IRL=Irlanda; ISL=Islandia; ISR=Israel; ITA=Italia; JPN=Japón; KAZ=Kazajistán; KHM=Camboya; $\mathrm{KOR}=$ Corea del Sur; LUX=Luxemburgo; LVA=Letonia; MAR=Marruecos; MEX=México; MLT=Malta; MYS=Malasia; NLD=Países Bajos; NOR=Noruega; 
se hace en dos planos: por un lado, se analiza el comercio de insumos entre sectores y, por otro lado, el valor agregado contenido en los mismos.

Respecto al comercio de insumos, se utilizó la tabla de demanda intermedia para calcular los coeficientes de Leontief de los bienes con un alto contenido de minerales y petróleo y medir, de acuerdo con Hirschman (1964), el grado de eslabonamientos generados a lo largo del proceso productivo. Entonces, al hacer la evaluación por país, se estima la capacidad de arrastre que tienen estos sectores sobre la economía nacional o sobre el extranjero, y con ello estimar cuán conectadas internamente están las economías proveedoras de materias primas. El cálculo de los coeficientes para un sector $j$ se realizan mediante la ecuación (1), en donde $I$ es la matriz identidad y $A$ la matriz de coeficientes técnicos (peso de un insumo $i$ en el valor bruto producido del sector $j$ ). La sumatoria de los coeficientes resultantes mide la capacidad de arrastre del sector $j$.

$$
B_{j}=\sum_{i=1}^{n}\left[(I-A)^{-1}\right]_{i, j}
$$

Además, los resultados de estos cálculos serán acompañados con indicadores de centralidad de la teoría de redes (que se explican líneas abajo) pues arrojan índices más reales.

Respecto a la evaluación del valor agregado, se toma la propuesta de Los et al. (2015) para obtener el valor agregado que se genera en cada industriapaís. Con ello se centra el análisis en cuánto es el aporte del sector minero de un país sobre el valor agregado total en una cadena productiva, y se muestran sus desplazamientos entre los ańos 1995 y 2011. El cálculo se hace con la ecuación (2).

$$
g=\hat{v}(I-A)^{-1} F e
$$

Aquí, $\hat{v}$ es un vector diagonalizado de coeficientes de valor agregado por cada unidad de valor bruto producido; $(I-A)^{-1}$ es el conocido inverso de Leontief; y, $\mathrm{Fe}$ es un vector columna que contiene la demanda final sólo para la industria-país que se desea evaluar.

NZL=Nueva Zelanda; PER=Perú; PHL=Filipinas; POL=Polonia; PRT=Portugal; ROU=Rumanía; ROW=Resto del Mundo; RUS=Rusia; SAU=Arabia Saudita; SGP=Singapur; svK=Eslovaquia; SVN=Eslovenia; $\mathrm{SWE}=$ Suecia; THA=Tailandia; $\mathrm{TUN}=$ Túnez; TUR=Turquía; TWN=Taiwán; USA=Estados Unidos de América; vNM=Vietnam; ZAF=Sudáfrica. 


\section{Herramientas del análisis de redes}

Así como las Tip se componen de un conjunto de sectores industriales y sus vínculos monetarios, en la teoría de redes sociales, una red está formada por un conjunto de nodos y sus respectivos enlaces. Si bien el coeficiente técnico y el coeficiente de Leontief miden los efectos directos e indirectos del crecimiento de una industria sobre el resto, por su forma de cálculo, el método supone que son posibles infinitos impactos sucesivos en un país, lo cual no es real. Así, el multiplicador mide el efecto potencial, más no el efectivo, del crecimiento de la demanda final de un sector (Schuschny, 2005). En contraste, los indicadores rango (Degree) y cercanía (Closeness) que ofrece la teoría de redes permiten precisar de manera más real el grado de alcance del crecimiento de un sector sobre el resto.

El concepto rango contabiliza el número de enlaces directos que tiene un nodo $p_{k}$ con el resto de nodos $p_{i}$ que forman una red de tamańo $n$, calculado de acuerdo a la ecuación (3). Así, cuanto mayor es el rango de una industria, puede transmitir su crecimiento con mayor efecto a los que están conectados directamente con ella, mientras que el impacto se debilita a medida que se alcanzan enlaces indirectos. Los enlaces representados por $a$ pueden tratarse de las compras que realiza un sector $p_{k}$ a $p_{i}$ (In Degree) o sus ventas (Out Degree), en valores monetarios (Borgatti y Everett, 2006). Al dividir los enlaces de cada nodo con el total de enlaces posibles en la red $(n-1)$, se obtiene una medida normalizada del rango, indicador que se usa en este trabajo.

$$
C_{D}\left(p_{k}\right)=\frac{\sum_{i=1}^{n} a\left(p_{i}, p_{k}\right)}{n-1}
$$

El concepto cercanía mide el número de saltos $d$ que requiere un nodo $p_{k}$ para llegar a todos los nodos $p_{i}$ de una red, de acuerdo con la ecuación (4). En nuestro contexto, indicaría cuán instantáneo (menor número de saltos) o cuán lento (mayor número de saltos) sería el efecto del crecimiento de una industria sobre sus sectores vinculados. Este vínculo puede darse a través de sus compras (In Closeness), o a través de sus ventas (Out Closeness) y se normaliza dividiéndolo entre el máximo de conexiones directas en una red (Freeman, 1979). Entendiendo que en una red más conectada el número de saltos es menor, se usa en inverso de este conteo; entonces, cuanto más alto es el índice, la cercanía entre los nodos es mayor. 


$$
C_{C}\left(p_{k}\right)=\left[\frac{\sum_{i=1}^{n} d\left(p_{i}, p_{k}\right)}{n-1}\right]^{-1}=\frac{n-1}{\sum_{i=1}^{n} d\left(p_{i}, p_{k}\right)}
$$

Estas y otras herramientas de la teoría de redes son usadas por García et al. (2008), Chai et al. (2011) y Noguera-Méndez et al. (2016) para estimar la centralidad de un sector y el grado de modularidad que forman grupos de nodos, y con ello revelan roles estratégicos de algunos sectores económicos que no surgen del análisis insumo-producto tradicional. En el presente documento, para el cálculo de estos índices, se utilizó el software Ucinet y el software Gephi para hacer visibles los enlaces más fuertes en la red de comercio de minerales.

\section{NODOS CENTRALES Y GENERACIÓN DE VALOR EN LAS CADENAS DE RECURSOS NATURALES}

\section{Nodos y eslabonamientos en las cadenas de valor de los recursos naturales}

Para obtener una visión general de los segmentos de producción en los que participan los recursos mineros en el mundo, se calcularon los coeficientes técnicos de la Tip del año 2011, agrupando los datos por sector industrial. La figura 1 muestra que los principales consumidores de minerales y petróleo son la industria de refinación de petróleo (42\%), la generación de electricidad y gas $(12 \%)$ y la manufactura de metales básicos (9\%). Partiendo de cada una de ellas, se muestra en la misma figura el porcentaje del valor bruto en que es vendido hacia adelante, formando los segmentos de producción a nivel mundial que hacen uso intensivo de minerales. Estas cadenas de producción terminan en algunos servicios como salud o en manufacturas como automóviles y equipos de cómputo. Por lo tanto, estos sectores, incluyendo sus intermediarios, son el objeto principal del presente análisis.

Al comparar las tip del año 1995 con las del 2011, se constata un cambio en las posiciones relativas en la producción mundial a favor de industrias de uso intensivo de minerales. El crecimiento del valor monetario producido por el sector minero, la refinería de petróleo y la manufactura de metales básicos sobresalen respecto al resto (véase figura 2 eje horizontal).

Una forma de identificar qué industria es la que podría haber impulsado tal crecimiento es a través del coeficiente de Leontief, calculado según la ecua- 
ción (1), pues la cifra resultante mide la capacidad de arrastre teórico de un sector. La misma figura 2 (eje vertical) muestra, de acuerdo a este indicador, que es la fabricación de automóviles la que ha generado los mayores impactos directos e indirectos al resto de industrias en el mundo, lo que se explica por la necesidad de absorber una diversidad de insumos provenientes de varios sectores, y revela así su papel como uno de los motores de crecimiento de la economía mundial. Seguido del sector de manufactura de metales básicos, y luego las industrias de equipos eléctricos, maquinaria y equipos, que son sectores que se abastecen de éste.

Identificado que las industrias de mayor crecimiento en la economía mundial son a su vez consumidoras de minerales y petróleo, a continuación se verá a qué países corresponden tales sectores. Con base en los 50 países-sectores de mayor demanda intermedia, la figura 3 los muestra ordenados según sus compras directas (In Degree) y sus ventas directas (Out Degree), excluyendo el autoconsumo.

Figura 1. Segmentos de producción internacional con uso intensivo de minerales y petróleo, año 2011

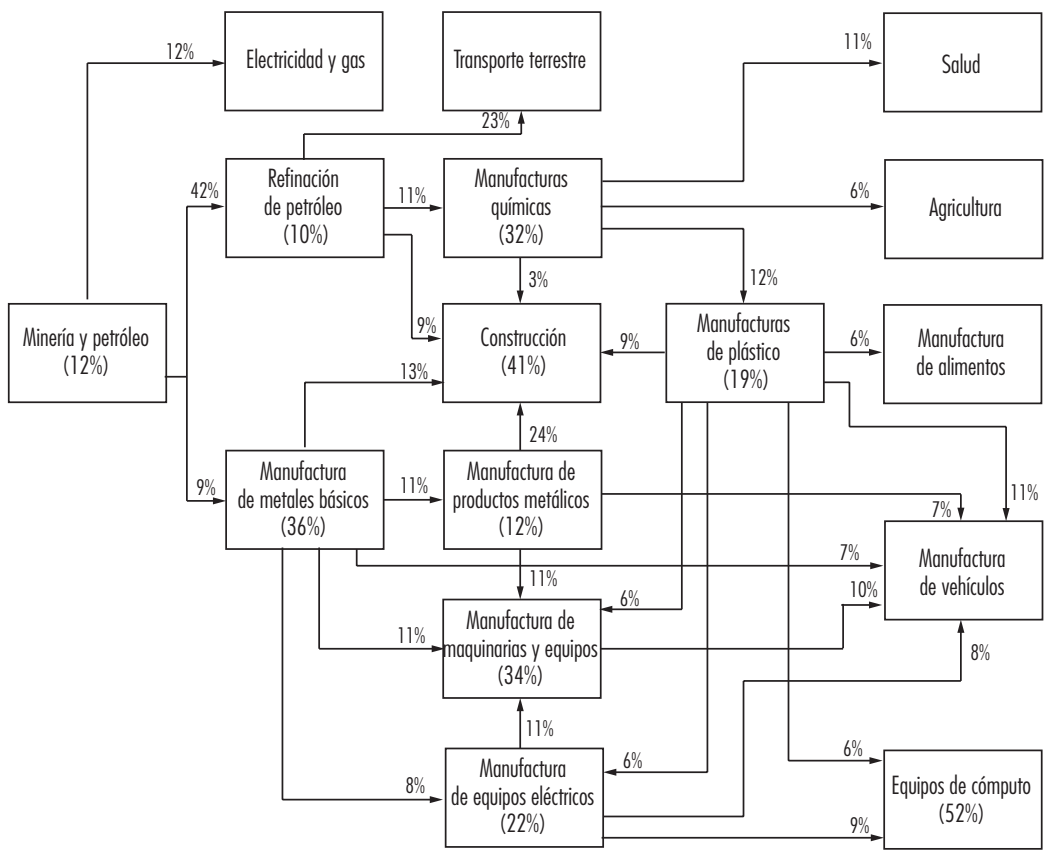

Nota: Las cifras muestran el porcentaje de las ventas de insumos de un sector a otro. En paréntesis, la venta hacia su mismo sector. Fuente de datos: OECD (2016). Cálculos y elaboración propios. 
Figura 2. Demanda intermedia 1995-2011 (var \%) y Coeficiente de Leontief por sectores, 2011

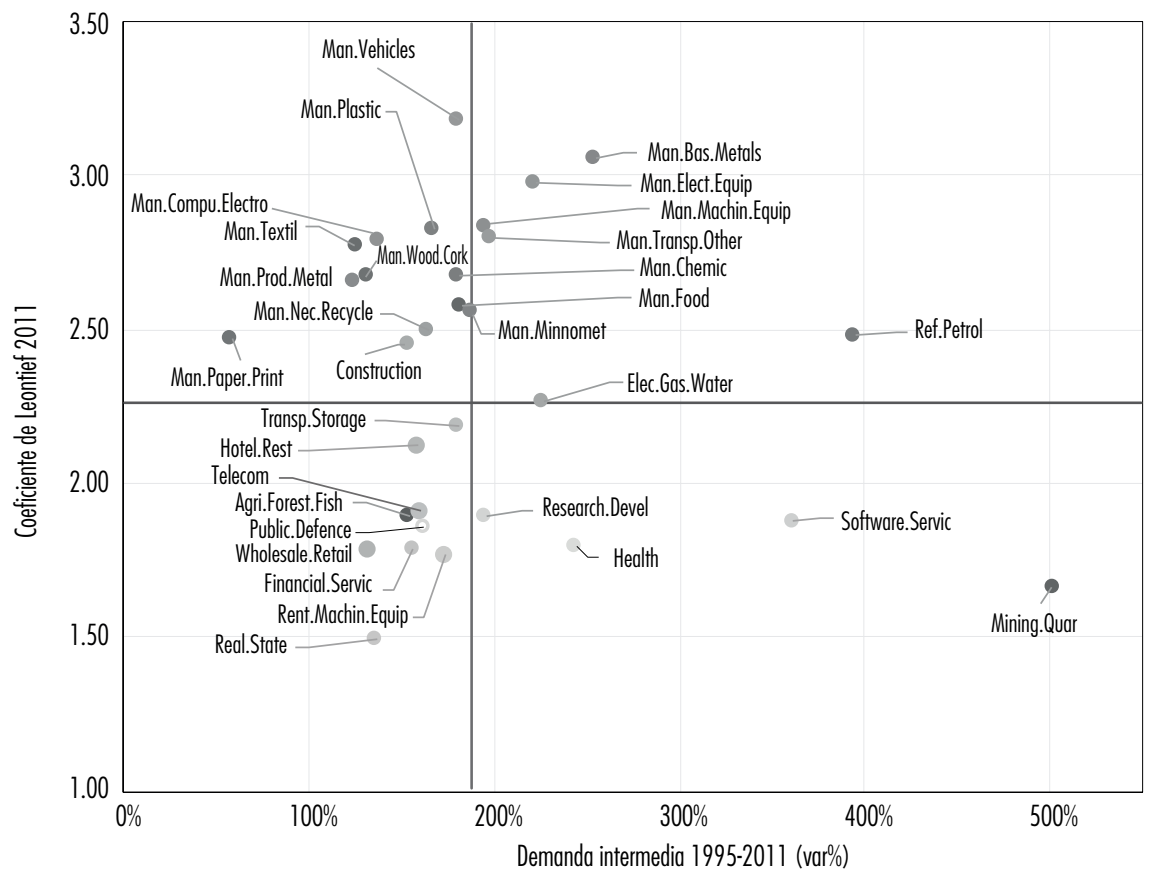

Nota: Ia línea vertical y horizontal representa el promedio de la variable respectiva.

Fuente: OECD (2016). Cálculos y elaboración propios.

Por un lado, las de mayor compra directa son industrias como la construcción, manufacturas químicas, de metales básicos y refinación de petróleo, de origen chino en su mayoría, pero también de Estados Unidos de América, Corea, India y Japón. Por otro lado, algunas manufacturas como vehículos y alimentos muestran un rango de salida bastante pequeño, debido a que sus ventas se realizan más como bien final que como bien intermedio, formando los últimos eslabones de las CGV. No tanto así para las manufacturas químicas, de metales básicos y de refinación de petróleo, que juegan el doble papel de adquirir minerales como insumo (alto rango de entrada) y ponerlo a disposición del resto de la industria, en forma de materia prima procesada (alto rango de salida), ubicándose como eslabones intermedios en los segmentos de producción.

Dado que la fabricación de vehículos y la construcción han influido de forma directa en la refinación de petróleo y la manufactura de metales básicos, sobre todo en China, Japón, Estados Unidos de América, Corea e India, se 
Figura 3. Rango de entrada y de salida de sectores de alto consumo de minerales, 2011

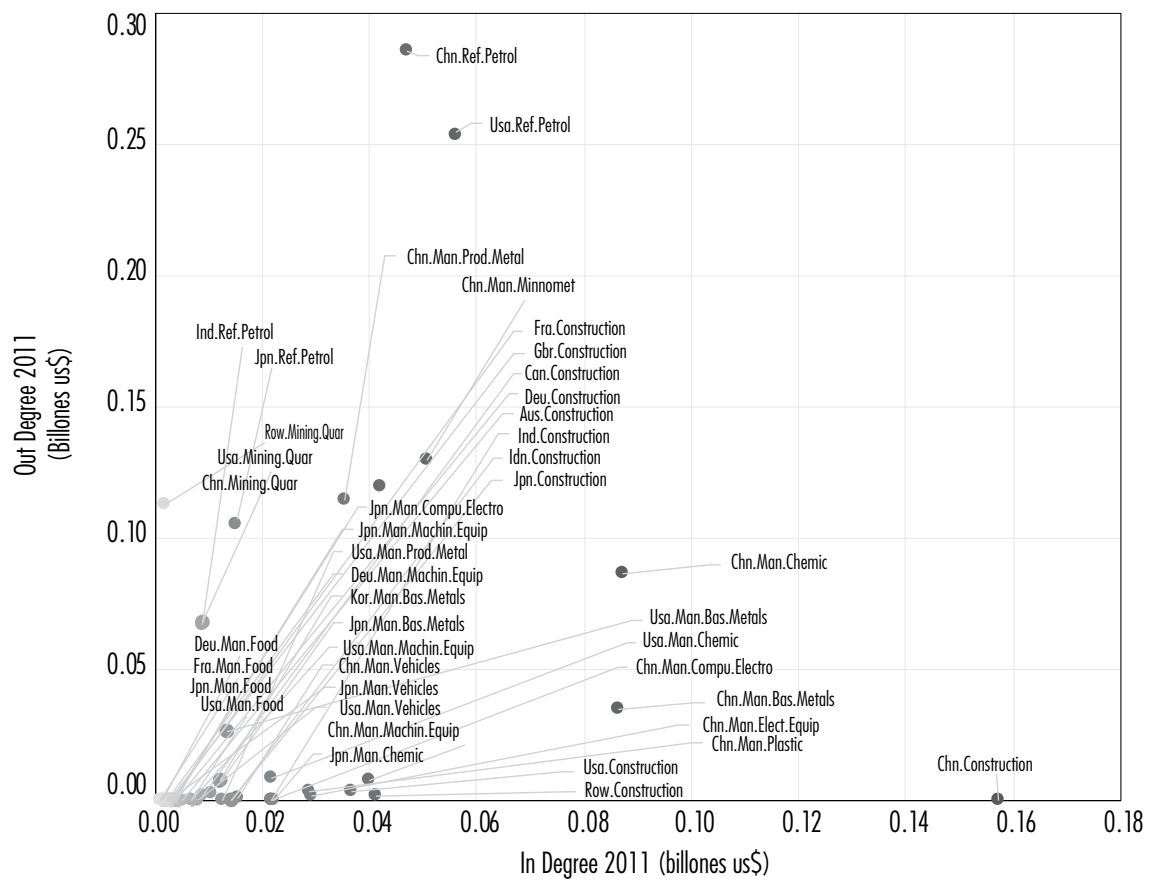

Fuente: : OECD (2016). Cálculos y elaboración propios.

entiende que ha sido gracias a la consolidación de una red mundial de abastecimiento de minerales. Una gran parte de esa red aparece en el mapa de la figura 4, en donde las líneas representan las compras de estos cinco países a sus principales proveedores. Se puede apreciar que en China, Estados Unidos de América y la India, su propio sector de minerales es el principal abastecedor, no obstante, al ser insuficientes deben recurrir a su importación.

En el caso de Corea y Japón el abastecimiento de minerales y petróleo proviene en su mayoría de fuera de su territorio. Así, los más grandes abastecedores son: Arabia Saudita, Canadá, Australia, México y Rusia; se agregan de Sudamérica: Brasil, Colombia, Chile, Perú, entre otros; del sureste asiático: Indonesia, Malasia y Brunéi, así como Sudáfrica; de Europa, más allá de Noruega y Reino Unido, el papel del resto de países es reducido. Se debe mencionar que un grupo de países importantes proveedores de minerales y petróleo del Medio Oriente y otras regiones del planeta están agrupados en el Resto del Mundo (ROw). 


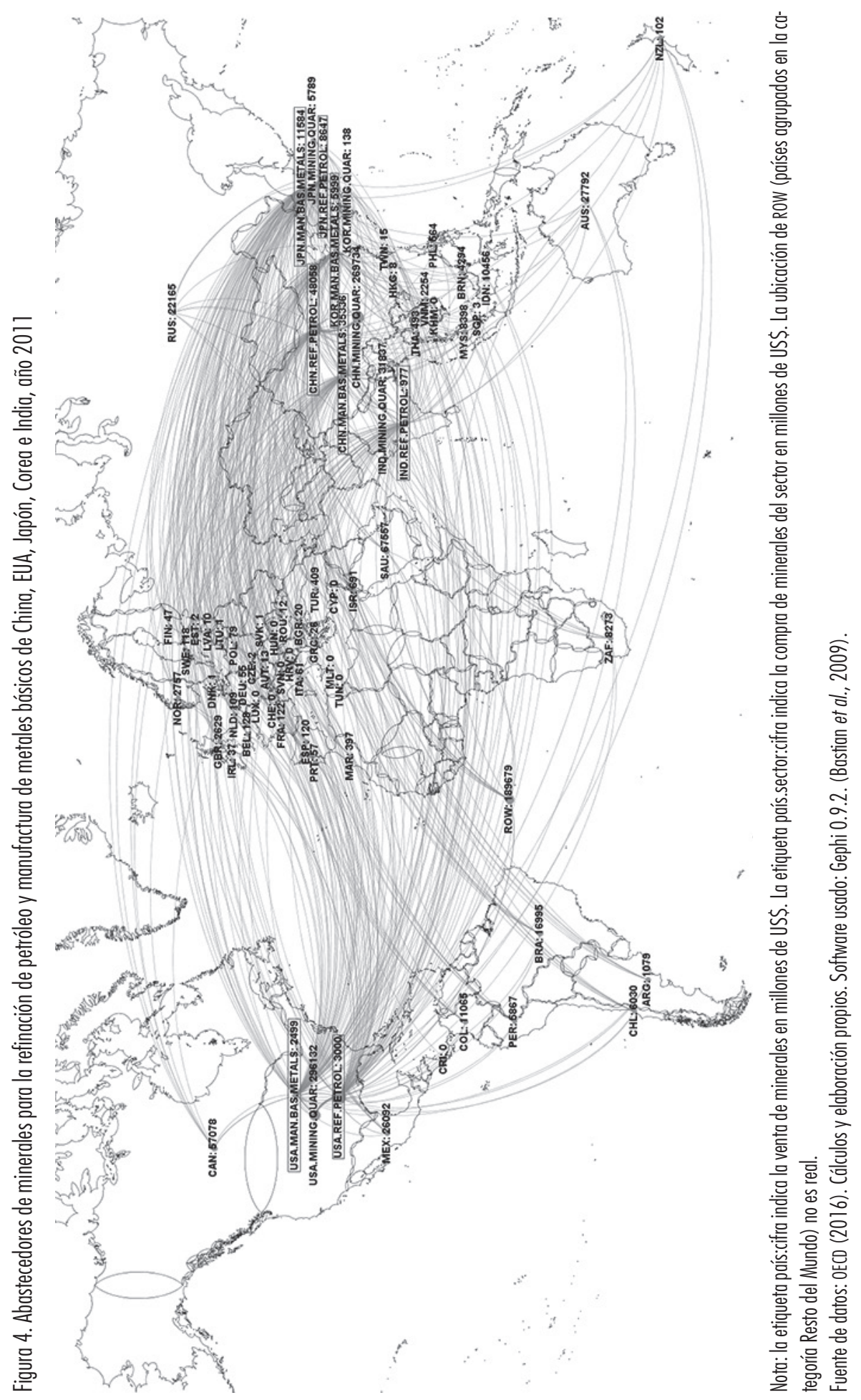


El alto consumo mundial de minerales debería haber tenido efectos sobre algunas variables macroeconómicas de los países abastecedores, dependiendo del peso de la materia prima en la canasta exportadora de cada uno. Así, el eje horizontal de la figura 5 muestra a Brunéi, Arabia Saudita, Perú, Colombia, Noruega y Australia como los países cuyas exportaciones mineras sobrepasan $40 \%$ del total exportado; en Rusia, Sudáfrica e India, alrededor del 30\%, y México, Chile, Brasil y Canadá, entre el 10 y 20\%.

El impacto del consumo mundial de minerales sobre estos países abastecedores ha sido diverso. Por ejemplo, las Reservas Netas de Divisas, que se alimentan de saldos favorables en las exportaciones netas, muestran un crecimiento promedio anual entre 40 y 50\% en Rusia, Arabia Saudita y Sudáfrica; en México del 24\%; en Brunéi, Perú, Australia, India, Brasil y Canadá entre 10 y $20 \%$, y en Colombia, Noruega y Chile un crecimiento algo por debajo del 10\% anual, entre 1995 y 2011 (The World Bank, 2018).

Por otro lado, se espera además que el aumento de las exportaciones mineras haya tenido un efecto expansivo hacia los sectores vinculados con la extracción a través de su red de comercio. Como se ha comentado, tal efecto se puede evaluar con ayuda del coeficiente de Leontief y con el índice de cercanía de la ecuación (4) de la sección anterior. No obstante, mientras que el primer indicador es influido fuertemente por el valor de la primera compra, en el segundo, la cifra resultante es más afectada por el número de enlaces directos e indirectos con otros sectores.

Así, la figura 5 muestra en el eje vertical el índice de cercanía de entrada de los países abastecedores. Se pueden identificar dos grupos: por un lado, países con un peso importante de minerales en sus exportaciones, pero con un bajo índice de cercanía, lo que indicaría que la demanda externa recibida no tendría un impacto muy extendido a través de sus compras a su red de comercio. Tal es el caso de Brunéi, Arabia Saudita, Perú, Colombia, Indonesia y Chile, entre otros. Por otro lado, hay países con un alto porcentaje de exportaciones de minerales y altos niveles de integración en sus redes de comercio, como Noruega, Australia, Rusia, Sudáfrica, Brasil y Canadá. En tanto que Malasia y México se ubican en el límite entre estos dos grupos.

Más aún, si se separa el índice de cercanía en su componente nacional y extranjero, el efecto local de las compras del sector exportador evaluado es también más pequeño en el primer grupo de los países mencionados. 
Figura 5. Peso del sector minero en las exportaciones e índice de cercanía del mismo sector en los principales países abastecedores, 2011

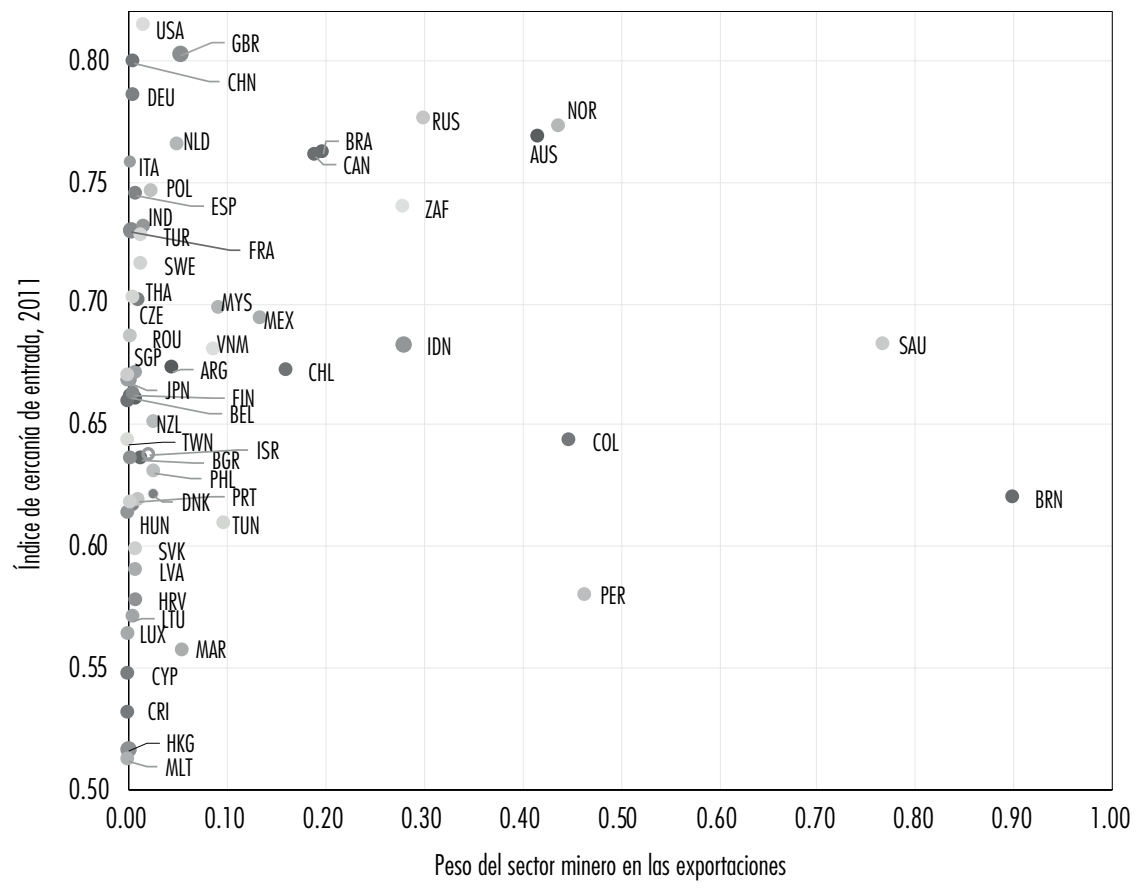

Fuente: OECD (2016). Cálculos y elaboración propios.

\section{Cambios en la generación de valor en la cadena de los recursos naturales}

Si bien el efecto del crecimiento de las exportaciones de minerales sobre algunas variables macroeconómicas es inmediato, se podría esperar que además estimule el escalamiento a eslabones de mayor valor agregado de los sectores favorecidos por la expansión de la demanda mundial. Una señal de tal cambio se puede obtener haciendo seguimiento al valor agregado en la matriz de demanda intermedia, calculado de acuerdo a la ecuación (2), buscando en qué sector la cifra resultante ha tenido un mayor crecimiento: en la extracción de bienes primarios, o en el sector que le añade valor por medio de su procesamiento, entendiendo que el procesamiento es una actividad más compleja que la extracción. 
El cuadro 1 muestra a la extracción minera y las industrias a cargo de su procesamiento en los principales países exportadores (se excluye a las economías avanzadas), y los principales países de destino. En cada caso, la columna 1 indica el porcentaje del valor agregado total generado por el sector y que es adquirido por un país específico, mientras que la columna 2 indica las veces que el crecimiento del valor agregado de ese sector supera al crecimiento promedio de aquéllos vinculados a la extracción minera y su procesamiento. Por ejemplo, en la columna 1 de la minería de Brasil se aprecia que 7.1\% de su valor agregado se destina a China y $2.5 \%$ a Estados Unidos de América y que, según la columna 2, ambos países han incentivado este crecimiento, superando 2 y 3.2 veces al promedio gracias a la demanda del primero y del segundo, respectivamente. Es decir, estos dos países han fortalecido tan sólo la actividad extractiva en Brasil, pues el resto de los sectores han crecido en una proporción menor. El efecto de la demanda de Japón, Corea e India sobre Brasil ha sido el mismo.

El cuadro muestra casos visibles de escalamiento en la industria química de Brunéi, la manufactura de metales básicos de Indonesia y la refinación de petróleo y manufactura de productos metálicos de Malasia. Aunque el cuadro no lo muestra, el encadenamiento de la minería hacia adelante llega en estos países a otros sectores, como la farmacéutica y la industria de alimentos en Brunéi; la manufactura de cerámica, vidrios y cemento y los equipos de transporte, en Indonesia, y maquinaria y equipos, equipos de transporte e industria de alimentos en Malasia.

Para entender el escalamiento en estos países asiáticos es necesario reconocer el uso de dos herramientas de política industrial aplicadas, como son los planes de desarrollo a largo plazo y el uso de los consejos de promoción de la inversión. Los planes de desarrollo descansan sobre un fundamento pragmático, pues combinan el papel económico activo del Estado y del capital privado. Son divididos en quinquenios, promueven la inversión nacional y extranjera orientada hacia los mercados externos y ven en la diversificación una vía para el crecimiento sostenible. En Brunéi, el plan vigente es el llamado Wawasan Brunei 2035 (Brunei Embassy Washington DC, 2018), lanzado en 2007, y que es la continuación del plan previo lanzado en 1985. Mientras que en Indonesia, se trata de un plan principal denominado National LongTerm Development Plan 2005-2025, acompañado de un plan medio y un plan maestro de aceleración del desarrollo económico (Ministry of National Development Planning, 2018). En Malasia, el Third Industrial Master Plan 2006-2020, que se enmarca en el llamado Vision 2020, lanzado en 1991 (MITI, 2018). 
Yuri Landa Arroyo

Cuadro 1. Valor agregado y su crecimiento en sectores vinculados a la minería en países proveedores, 1995-2011

\begin{tabular}{|c|c|c|c|c|c|c|c|c|c|c|c|}
\hline \multirow[t]{2}{*}{ País } & \multirow[t]{2}{*}{ Sector } & \multicolumn{2}{|c|}{$J P N$} & \multicolumn{2}{|c|}{ KOR } & \multicolumn{2}{|c|}{ USA } & \multicolumn{2}{|c|}{ CHN } & \multicolumn{2}{|c|}{ IND } \\
\hline & & (1) & (2) & (1) & (2) & (1) & (2) & (1) & (2) & (1) & (2) \\
\hline \multirow[t]{5}{*}{ BRA } & MINING.QUAR & 2.0 & 3.0 & 0.7 & 2.1 & 2.5 & 3.2 & 7.1 & 2.0 & 1.0 & 2.1 \\
\hline & REF.PETROL & 0.2 & 0.4 & 0.1 & 0.8 & 0.6 & 0.4 & 0.7 & 0.8 & 0.1 & 0.6 \\
\hline & MAN.CHEMIC & 0.1 & 0.5 & 0.1 & 0.5 & 0.5 & 0.7 & 0.5 & 0.9 & 0.1 & 0.6 \\
\hline & MAN.BAS.METALS & 0.9 & 0.8 & 0.7 & 0.8 & 2.4 & 0.7 & 1.5 & 0.7 & 0.6 & 0.8 \\
\hline & MAN.PROD.METAL & 0.2 & 0.9 & 0.1 & 1.1 & 0.8 & 0.7 & 0.7 & 1.0 & 0.1 & 1.0 \\
\hline \multirow[t]{5}{*}{ BRN } & MINING.QUAR & 22.4 & 2.7 & 5.1 & 1.7 & 0.6 & 2.9 & 4.5 & 2.3 & 3.7 & 3.1 \\
\hline & REF.PETROL & 4.5 & -0.7 & 1.0 & -0.1 & 0.2 & 0.0 & 1.7 & 0.3 & 0.9 & 1.1 \\
\hline & MAN.CHEMIC & 2.2 & 7.5 & 3.6 & 5.1 & 1.9 & 1.2 & 7.0 & 2.0 & 0.8 & 0.3 \\
\hline & MAN.BAS.METALS & 2.1 & -0.8 & 1.7 & 0.2 & 6.6 & 2.6 & 3.3 & 0.4 & 2.7 & 0.8 \\
\hline & MAN.PROD.METAL & 1.2 & -0.5 & 0.4 & 0.1 & 0.6 & -0.1 & 1.5 & 0.4 & 0.7 & 0.6 \\
\hline \multirow[t]{5}{*}{ CHL } & MINING.QUAR & 11.8 & 2.6 & 2.4 & 1.9 & 1.7 & 1.0 & 12.3 & 1.6 & 3.9 & 2.3 \\
\hline & REF.PETROL & 1.2 & 1.1 & 0.4 & 1.1 & 0.7 & 0.9 & 2.5 & 0.7 & 0.4 & 1.1 \\
\hline & MAN.CHEMIC & 0.8 & -0.1 & 0.4 & 0.3 & 1.3 & 0.1 & 1.5 & 0.3 & 0.4 & 0.4 \\
\hline & MAN.BAS.METALS & 1.6 & 1.2 & 2.9 & 1.4 & 4.3 & 1.7 & 15.1 & 2.1 & 0.6 & 0.4 \\
\hline & MAN.PROD.METAL & 0.8 & 0.3 & 0.3 & 0.5 & 0.6 & 0.3 & 1.7 & 0.7 & 0.3 & 0.6 \\
\hline \multirow[t]{5}{*}{$\mathrm{COL}$} & MINING.QUAR & 0.6 & 1.5 & 0.4 & 1.6 & 17.0 & 1.0 & 3.3 & 1.7 & 1.3 & 1.8 \\
\hline & REF.PETROL & 0.1 & 2.0 & 0.1 & 1.5 & 2.3 & 2.0 & 0.3 & 1.3 & 0.2 & 2.2 \\
\hline & MAN.CHEMIC & 0.1 & 0.3 & 0.1 & 0.5 & 0.7 & 0.3 & 0.2 & 0.4 & 0.1 & 0.4 \\
\hline & MAN.BAS.METALS & 0.6 & 2.3 & 1.2 & 1.8 & 13.0 & 2.2 & 5.5 & 1.8 & 0.6 & 0.9 \\
\hline & MAN.PROD.METAL & 0.0 & 0.2 & 0.0 & 0.5 & 1.2 & 0.6 & 0.2 & 0.6 & 0.1 & 0.6 \\
\hline \multirow[t]{5}{*}{ IDN } & MINING.QUAR & 8.6 & 0.8 & 3.5 & 0.9 & 0.9 & 1.1 & 7.7 & 1.2 & 3.4 & 1.3 \\
\hline & REF.PETROL & 1.5 & 0.7 & 0.5 & 0.8 & 0.2 & 0.3 & 0.9 & 0.8 & 0.3 & 0.5 \\
\hline & MAN.CHEMIC & 0.8 & 0.8 & 0.4 & 0.8 & 0.6 & 1.2 & 2.1 & 1.0 & 0.6 & 0.4 \\
\hline & MAN.BAS.METALS & 11.8 & 1.3 & 3.1 & 1.5 & 2.2 & 1.6 & 5.4 & 1.4 & 2.1 & 1.1 \\
\hline & MAN.PROD.METAL & 0.4 & 0.6 & 0.1 & 0.8 & 0.2 & 0.1 & 0.2 & 0.5 & 0.4 & 1.7 \\
\hline
\end{tabular}




\begin{tabular}{|c|c|c|c|c|c|c|c|c|c|c|c|}
\hline \multirow[t]{2}{*}{ País } & \multirow[t]{2}{*}{ Sector } & \multicolumn{2}{|c|}{$J P N$} & \multicolumn{2}{|c|}{ KOR } & \multicolumn{2}{|c|}{ USA } & \multicolumn{2}{|c|}{ CHN } & \multicolumn{2}{|c|}{ IND } \\
\hline & & (1) & (2) & (1) & (2) & (1) & (2) & (1) & (2) & (1) & (2) \\
\hline \multirow[t]{5}{*}{ MEX } & MINING.QUAR & 0.4 & 0.5 & 0.3 & 2.0 & 13.8 & 1.4 & 1.6 & 2.4 & 0.8 & 2.2 \\
\hline & REF.PETROL & 0.1 & -0.1 & 0.1 & 0.4 & 2.5 & 0.7 & 0.2 & 0.5 & 0.1 & 0.6 \\
\hline & MAN.CHEMIC & 0.2 & 0.1 & 0.1 & 0.4 & 3.4 & 0.5 & 0.5 & 0.5 & 0.2 & 0.3 \\
\hline & MAN.BAS.METALS & 0.8 & 1.5 & 0.9 & 1.2 & 15.8 & 1.3 & 1.6 & 0.8 & 0.7 & 0.9 \\
\hline & MAN.PROD.METAL & 0.2 & 1.6 & 0.1 & 1.1 & 10.9 & 1.1 & 0.4 & 1.0 & 0.1 & 1.1 \\
\hline \multirow[t]{5}{*}{ MYS } & MINING.QUAR & 13.4 & 1.0 & 2.5 & 0.9 & 0.7 & 0.7 & 5.3 & 0.9 & 2.9 & 0.7 \\
\hline & REF.PETROL & 2.3 & 1.7 & 0.9 & 1.2 & 0.5 & 2.6 & 3.4 & 1.6 & 0.8 & 1.7 \\
\hline & MAN.CHEMIC & 1.8 & 0.9 & 0.9 & 0.7 & 1.2 & 0.8 & 5.1 & 0.7 & 1.4 & 0.8 \\
\hline & MAN.BAS.METALS & 3.4 & 0.7 & 2.8 & 0.8 & 2.1 & 0.7 & 12.0 & 1.2 & 6.9 & 0.7 \\
\hline & MAN.PROD.METAL & 2.0 & 2.1 & 0.7 & 1.8 & 1.3 & 1.3 & 3.1 & 1.4 & 1.5 & 1.9 \\
\hline \multirow[t]{5}{*}{ PER } & MINING.QUAR & 4.9 & 1.1 & 2.7 & 1.4 & 3.9 & 0.6 & 12.3 & 1.2 & 1.0 & 1.4 \\
\hline & REF.PETROL & 0.9 & 2.5 & 0.3 & 1.6 & 3.1 & 1.3 & 1.4 & 1.5 & 0.2 & 1.3 \\
\hline & MAN.CHEMIC & 0.3 & 0.9 & 0.1 & 1.1 & 0.5 & 0.8 & 0.8 & 0.8 & 0.1 & 0.8 \\
\hline & MAN.BAS.METALS & 1.1 & 0.1 & 0.5 & 0.2 & 11.6 & 1.0 & 5.2 & 0.4 & 2.6 & 0.8 \\
\hline & MAN.PROD.METAL & 0.1 & 0.3 & 0.1 & 0.2 & 0.3 & 0.4 & 0.2 & 0.4 & 0.0 & 0.6 \\
\hline \multirow[t]{5}{*}{ SAU } & MINING.QUAR & 8.5 & 1.7 & 3.7 & 1.1 & 6.2 & 0.8 & 7.3 & 2.1 & 5.1 & 1.1 \\
\hline & REF.PETROL & 2.6 & 0.2 & 2.1 & 0.4 & 0.6 & 0.4 & 1.9 & 0.3 & 2.1 & 0.8 \\
\hline & MAN.CHEMIC & 0.7 & 0.8 & 0.7 & 0.9 & 1.1 & 0.8 & 7.4 & 1.2 & 2.0 & 0.5 \\
\hline & MAN.BAS.METALS & 1.0 & 1.2 & 1.0 & 1.3 & 1.0 & 1.3 & 1.2 & 0.8 & 4.4 & 0.9 \\
\hline & MAN.PROD.METAL & 0.0 & 0.2 & 0.0 & 0.3 & 0.0 & 0.1 & 0.1 & 0.0 & 0.1 & 0.6 \\
\hline \multirow[t]{5}{*}{ ZAF } & MINING.QUAR & 3.1 & 2.3 & 1.3 & 1.8 & 1.7 & 1.9 & 11.8 & 2.1 & 5.7 & 1.4 \\
\hline & REF.PETROL & 0.4 & 3.1 & 0.1 & 2.1 & 0.4 & 2.5 & 0.7 & 1.4 & 0.7 & 1.4 \\
\hline & MAN.CHEMIC & 0.7 & 0.2 & 0.2 & 0.5 & 1.2 & 0.7 & 1.6 & 0.6 & 1.4 & 0.3 \\
\hline & MAN.BAS.METALS & 5.8 & 0.3 & 2.0 & 0.6 & 3.6 & 0.2 & 5.5 & 0.7 & 15.5 & 1.5 \\
\hline & MAN.PROD.METAL & 0.7 & -0.4 & 0.3 & 0.3 & 0.8 & 0.1 & 1.7 & 0.5 & 1.4 & 0.6 \\
\hline
\end{tabular}

Notas: (1) Porcentaje del valor agregado generado por el sector exportador, según destino, 2011; (2) Veces que el crecimiento del valor agregado del sector supera el promedio en las industrias vinculadas a la minería, 1995-2011.

Fuente: elaboración propia. 
Los consejos de promoción de la inversión son entidades gubernamentales que sirven como espacio de vínculo entre diversos ministerios y el sector privado o la sociedad civil. En Brunéi e Indonesia, los consejos responden directamente al sultán y a la presidencia, respectivamente; en Malasia responden al Ministerio de Comercio Internacional e Industria. Los consejos tienen como función facilitar la inversión a través de la difusión de oportunidades, de servicios de asistencia, entre otros, así como generar la propuesta y el monitoreo de políticas que promuevan la inversión, de acuerdo con las metas establecidas en los planes de desarrollo respectivos. El uso de estas herramientas ha dado como resultado mejoras en infraestructura, la formación del capital humano y el establecimiento de clústeres industriales, todo lo cual, aunado al establecimiento de zonas económicas especiales, ha logrado formar en países del sudeste del Asia una industria local encadenada a las CGV (López, 2014; Ramírez, 2017).

En el resto de países-sectores del cuadro 1, el escalamiento no se muestra de manera contundente. La refinación de petróleo es una industria extendida en países exportadores de este recurso, sin embargo, el cuadro muestra que los casos en que la demanda hacia la refinación supera a la que recibe la actividad extractiva ocurre de manera puntual, siendo Perú y Sudáfrica los de más ocurrencias. Lo mismo sucede con la industria de metales básicos que acompaña a la extracción de minerales y que, de acuerdo al cuadro, en Colombia y Chile reciben algún estímulo de los países consumidores.

Esto concuerda con los resultados de Rodil (2017), quien encuentra que la participación del valor generado en Brasil, Chile y Colombia en las exportaciones de bienes elaborados por otros países creció significativamente desde 1995, indicando el reforzamiento de la participación de estos países en las primeras etapas de las CGV. Mientras que, para México, de acuerdo con Pérez (2017), a pesar de que sus exportaciones de metales básicos han aumentado, el contenido importado de las mismas creció mucho más, reduciéndose así el peso relativo del valor agregado local. Así, el efecto industrializador de tal escalamiento es muy limitado.

Por otro lado, el mismo cuadro muestra que, entre los cinco países compradores analizados, las cifras indican que China e India son los países cuya demanda ha servido para fortalecer más el carácter extractivo de los países abastecedores. 


\section{GOBERNANZA EN LAS CGV DE LOS RECURSOS NATURALES}

En este punto del análisis es necesario incluir el papel de las empresas transnacionales que gobiernan los segmentos de producción que hacen uso intensivo de minerales, pues las opciones de escalamiento de las unidades productivas locales nacionales o extranjeras a lo largo de la cadena y, por lo tanto, el posible impacto industrializador sobre el resto de la economía, están condicionadas por las estrategias de las empresas líderes.

Si bien el enfoque de CGV se desarrolla para analizar lo ocurrido con la transnacionalización de la producción en las últimas décadas del siglo Xx, para el caso del uso de recursos mineros esta internacionalización ocurre mucho antes. $\mathrm{Al}$ respecto, el cuadro 2 muestra un grupo de transnacionales de mayor presencia en el mundo vinculadas a la extracción y al procesamiento de minerales. La información se obtuvo en cada caso del portal web respectivo y, dado el número amplio de empresas, se resaltan a continuación algunos patrones comunes en cuanto a sus estrategias de gobernanza.

De acuerdo a la procedencia de las empresas se pueden clasificar en dos grupos: las de origen anglosajón y las de origen asiático. Las empresas petroleras de origen anglosajón se fundaron en la segunda mitad del siglo xIx y se sabe que su transnacionalización ocurre hacia inicios del siglo $\mathrm{xx}$. Todas las empresas mostradas en el cuadro 2 han construido cadenas de producción vertical que empiezan con la extracción de petróleo/gas, pasan por la refinación/licuefacción y llegan por lo menos a la industria química, o bien, hasta la generación de energía. Los encadenamientos hacia atrás y la gobernanza que aplican sus filiales extractivas dependen de las condiciones del país anfitrión al momento de su llegada y su posterior desarrollo.

En economías de poco desarrollo industrial llegan a formar enclaves de tal manera que los encadenamientos con la producción local son muy limitados, predominando el estilo de gobernanza jerárquico, pues instalan sucursales que se limitan a garantizar el suministro al exterior del combustible. De esa manera, la economía local está desligada de la cadena global de valor, tal como es todavía el caso actual de varias localidades en Latinoamérica. Sin embargo, las mismas transnacionales adoptan estrategias de gobernanza relacional ante gobiernos con políticas industriales claramente definidas, como las economías asiáticas en la actualidad, hasta el punto de formar alianzas con empresas estatales locales, como es el caso de Shell en Brunéi, que comparte $50 \%$ la propiedad de la extracción de petróleo; Exxon y Pertamina en la extracción en Indonesia, у вр у Petronas en la industria petroquímica en Malasia. 
Cuadro 2. Transnacionales líderes en las cadenas de recursos naturales

\begin{tabular}{|c|c|c|c|}
\hline Empresa & Sectores & Países* & Abastece a sector \\
\hline $\begin{array}{l}\text { Royal Dutch Shell, } \\
\text { Reino Unido, } 1833\end{array}$ & $\begin{array}{l}\text { Minería, Refinación, Química, } \\
\text { Energía }\end{array}$ & Brunéi, Malasia & $\begin{array}{l}\text { Comercialización (combustibles y } \\
\text { lubricantes), Qúmica, Plásticos }\end{array}$ \\
\hline $\begin{array}{l}\text { BHP Billiton, } \\
\text { Australia, } 1851\end{array}$ & Minería, Metales básicos & $\begin{array}{l}\text { Brasil, Chile, Colombia, } \\
\text { Perú }\end{array}$ & Metales básicos, Química, Energía \\
\hline $\begin{array}{l}\text { Exxon Mobil, Estados } \\
\text { Unidos de América, } \\
1859\end{array}$ & $\begin{array}{l}\text { Minería, Refinación de petróleo, } \\
\text { Química }\end{array}$ & $\begin{array}{l}\text { Brasil, Colombia, } \\
\text { Indonesia, Malasia, } \\
\text { Sudáfrica }\end{array}$ & $\begin{array}{l}\text { Comercialización (combustibles y } \\
\text { lubricantes), Plásticos, Equipos de } \\
\text { transporte }\end{array}$ \\
\hline $\begin{array}{l}\text { Río Tinto, Reino } \\
\text { Unido, } 1873\end{array}$ & Minería, Metales básicos & Brasil, Chile, Indonesia & $\begin{array}{l}\text { Comercialización, Metales básicos, } \\
\text { Equipos de transporte }\end{array}$ \\
\hline $\begin{array}{l}\text { Mitsubishi } \\
\text { Corporation, Japón, } \\
1873\end{array}$ & $\begin{array}{l}\text { Minería, Metales básicos, Química, } \\
\text { Maquinaria y Equipo, Equipos de } \\
\text { transporte, Infraestructura, Energía, } \\
\text { Finanzas, Alimentos procesados, } \\
\text { Comercialización }\end{array}$ & $\begin{array}{l}\text { Arabia Saudita, Brasil, } \\
\text { Brunéi, Chile, Indonesia, } \\
\text { Malasia, México }\end{array}$ & $\begin{array}{l}\text { Comercialización, Metales básicos, } \\
\text { Química, Maquinaria y Equipo, } \\
\text { Infraestructura, Energía }\end{array}$ \\
\hline $\begin{array}{l}\text { Chevron Corp, } \\
\text { Estados Unidos de } \\
\text { América, } 1876\end{array}$ & $\begin{array}{l}\text { Minería, Refinación de petróleo, } \\
\text { Química }\end{array}$ & $\begin{array}{l}\text { Arabia Saudita, Brasil, } \\
\text { Colombia, Indonesia, } \\
\text { México }\end{array}$ & $\begin{array}{l}\text { Comercialización (combustibles y } \\
\text { lubricantes), Química, Plásticos }\end{array}$ \\
\hline $\begin{array}{l}\text { BP, Reino } \\
\text { Unido,1908 }\end{array}$ & $\begin{array}{l}\text { Minería, Refinación, Química, } \\
\text { Energía, Servicios de ingeniería, } \\
\text { Comercialización }\end{array}$ & Brasil, Indonesia, Malasia & $\begin{array}{l}\text { Comercialización (combustibles y } \\
\text { lubricantes), Química, Plásticos, } \\
\text { Equipos de transporte }\end{array}$ \\
\hline $\begin{array}{l}\text { Total S.A., Francia, } \\
1924\end{array}$ & $\begin{array}{l}\text { Minería, Refinación de petróleo, } \\
\text { Química }\end{array}$ & $\begin{array}{l}\text { Arabia Saudita, Brasil, } \\
\text { Brunéi, Indonesia, México, } \\
\text { Sudáfrica }\end{array}$ & $\begin{array}{l}\text { Comercialización (combustibles y } \\
\text { lubricantes), Equipos de transporte }\end{array}$ \\
\hline $\begin{array}{l}\text { Glencore, Suiza, } \\
1974 \text { (Xtrata, } \\
\text { 1926) }\end{array}$ & $\begin{array}{l}\text { Minería, Metales básicos, } \\
\text { Agricultura, Comercialización }\end{array}$ & Argentina, Chile, Perú & $\begin{array}{l}\text { Metales básicos, Química, } \\
\text { Comercialización, Alimentos } \\
\text { procesados }\end{array}$ \\
\hline $\begin{array}{l}\text { Grupo Repsol, } \\
\text { España, } 1927\end{array}$ & $\begin{array}{l}\text { Minería, Refinación, Química, } \\
\text { Energía }\end{array}$ & $\begin{array}{l}\text { Colombia, Indonesia, } \\
\text { México, Perú }\end{array}$ & $\begin{array}{l}\text { Comercialización (combustibles y } \\
\text { lubricantes), Química, Plásticos, } \\
\text { Equipos de transporte, Energía }\end{array}$ \\
\hline $\begin{array}{l}\text { Oil and Natural Gas } \\
\text { Corporation Limited, } \\
\text { India, } 1947\end{array}$ & Minería, Refinación de petróleo & Brasil, Colombia & $\begin{array}{l}\text { Comercialización (combustibles y } \\
\text { lubricantes), Química }\end{array}$ \\
\hline $\begin{array}{l}\text { China Minmetals } \\
\text { Corporation, } 1950 \\
\text { (MMG Limited, } \\
\text { 2009) }\end{array}$ & $\begin{array}{l}\text { Minería, Metales básicos, Servicios } \\
\text { de Ingeniería, Construcción, } \\
\text { Finanzas, Comercialización }\end{array}$ & Perú & $\begin{array}{l}\text { Comercialización, Minería, Metales } \\
\text { básicos, Construcción }\end{array}$ \\
\hline $\begin{array}{l}\text { Reliance Industries } \\
\text { Limited, India, } 1957\end{array}$ & $\begin{array}{l}\text { Minería, Refinación de petróleo, } \\
\text { Química, Textil }\end{array}$ & Malasia & $\begin{array}{l}\text { Comercialización, Química, Plásticos, } \\
\text { Textil, Equipos de transporte }\end{array}$ \\
\hline
\end{tabular}




\begin{tabular}{|c|c|c|c|}
\hline Empresa & Sectores & Países* & Abastece a sector \\
\hline $\begin{array}{l}\text { SK Innovation, Corea } \\
\text { del Sur, } 1962\end{array}$ & $\begin{array}{l}\text { Minería, Refinación, Química, } \\
\text { Maquinaría y Equipos, Transporte }\end{array}$ & Perú & $\begin{array}{l}\text { Comercialización (combustibles y } \\
\text { lubricantes), Química, Plásticos, } \\
\text { Equipos de transporte }\end{array}$ \\
\hline $\begin{array}{l}\text { Posco, Corea del Sur, } \\
1967\end{array}$ & $\begin{array}{l}\text { Minería, Metales básicos, Química, } \\
\text { Energía }\end{array}$ & $\begin{array}{l}\text { Brasil, Indonesia, Malasia, } \\
\text { México }\end{array}$ & $\begin{array}{l}\text { Comercialización, Metales básicos, } \\
\text { Química, Maquinaria y Equipo, Equipos } \\
\text { de transporte, Construcción, Energía }\end{array}$ \\
\hline $\begin{array}{l}\text { Nippon Steel and } \\
\text { Sumitomo Metal, } \\
\text { Japón, } 1970\end{array}$ & Metales básicos, Química & $\begin{array}{l}\text { Arabia Saudita, Brasil, } \\
\text { Indonesia, Malasia, } \\
\text { México, Sudáfrica }\end{array}$ & $\begin{array}{l}\text { Metales básicos, Química, Maquinaria } \\
\text { y Equipo, Equipos de transporte, } \\
\text { Construcción }\end{array}$ \\
\hline $\begin{array}{l}\text { China National } \\
\text { Petroleum } \\
\text { Corporation, } 1988 \\
\text { (PetroChina Company } \\
\text { Limited, 1999) }\end{array}$ & $\begin{array}{l}\text { Minería, Refinación de petróleo, } \\
\text { Química, Maquinaria y equipos, } \\
\text { Servicios de Ingeniería, } \\
\text { Construcción, Finanzas, } \\
\text { Comercialización }\end{array}$ & Brasil, Indonesia, Perú & $\begin{array}{l}\text { Comercialización (combustibles y } \\
\text { lubricantes), Química, Maquinaria } \\
\text { y equipos, Servicios de Ingeniería, } \\
\text { Construcción }\end{array}$ \\
\hline
\end{tabular}

Nota: *se menciona sólo a los referidos en el cuadro 1.

Fuente: elaboración propia.

Respecto al encadenamiento hacia adelante, es común que la actividad de la refinación acompañe a la extracción en el país anfitrión, no obstante, más allá de eso, abastecen de insumos a industrias fuera del país de extracción, como la química, de plásticos y al sector automotriz ubicados en diversas regiones del mundo, formando parte de CGV de bienes finales, en las cuales el liderazgo ya no está en sus manos sino en el de las empresas que ofrecen el bien final. Sin embargo, sí controlan directa o indirectamente la cadena de combustible que llega al consumidor final a través de estaciones de servicio. En ese sector, dado el modelo de negocio predominante, la gobernanza es cautiva, pues la empresa líder suscribe acuerdos verticales con los dueños de las gasolinerías que se encargarán de distribuir el bien, con requisitos de exclusividad y de control de precios.

En cuanto a las empresas mineras de origen anglosajón, se asemejan a las petroleras en la medida en que la extracción y algunos procesos de refinación se realizan en el país anfitrión, bajo una gobernanza jerárquica, y con un encadenamiento hacia atrás muy limitado, en el caso de Latinoamérica. Por el tipo de bien que ofrecen (productos metálicos) no llegan a ser líderes de cadenas de valor de bienes finales, aunque sí forman parte de los segmentos de producción que terminan en el sector de la construcción, de maquinaria y equipos, de equipos de cómputo y de la industria automotriz. 
Las empresas de origen asiático, con excepción de Mitsubishi, nacen después de la Segunda Guerra Mundial, bajo el contexto de la formación de nuevos países o formas de gobierno en Asia, y de acuerdo con el sentimiento nacionalista predominante, son empresas estatales o privadas que están sometidas a estrategias gubernamentales de crecimiento (López, 2014). Así, Minmetals y la National Petroleum Corporation son empresas estatales chinas; Posco y sK son conglomerados coreanos multisectoriales y de control familiar, y Mitsubishi y Sumimoto son conglomerados japoneses que, a diferencia de los coreanos, incluyen un brazo financiero.

Casi a la par de su nacimiento, estas empresas empiezan su proceso de transnacionalización en la búsqueda de minerales y petróleo para hacer posible el crecimiento económico planificado, lo que en los años 2000 será potenciado por sus respectivos gobiernos gracias a la firma de acuerdos comerciales ad hoc (Wilson, 2014). Establecen una gobernanza jerárquica con las sucursales en los países de abundantes recursos mineros, y además relacional, cuando deben formar alianzas con empresas estatales, privadas locales o inclusive transnacionales ya existentes.

A diferencia de las transnacionales anglosajonas, ya sea petroleras o mineras, se trata de empresas integradas verticalmente, formando cadenas de producción que van desde la extracción, la refinación y la industria química, hasta la construcción, la fabricación de maquinaria y equipos, de equipos de transporte, la generación de energía y comercialización; inclusive con negocios laterales como los servicios de ingeniería y las finanzas. Es decir, son empresas líderes en cadenas de valor completas, que terminan en bienes y servicios finales. Dado el origen estatal o familiar de estas corporaciones, de acuerdo a Carney (2005), la gestión de la cadena está sustentada en el control de la propiedad de las empresas que la componen; en contraste, las redes occidentales están formadas por empresas vinculadas con base en contratos.

Los encadenamientos hacia atrás o adelante con la producción local de los países en donde invierten dependen de cuán avanzada está la internacionalización de su propio proceso productivo, así como de las capacidades y oportunidades que ofrece el país anfitrión. Dado sus años de existencia, Mitsubishi es un caso de internacionalización muy avanzado; es así como en Chile participa en la producción de fierro; en México produce plásticos; en Brunéi, produce gas natural licuado; en Indonesia fabrica autos, y tiene una sucursal de consultoría financiera y de negocios en Malasia. Por otro lado, la empresa Posco de Corea, especializada en la producción de acero, obtiene la materia prima principalmente de Canadá, Nueva Caledonia y Rusia, y también procesa me- 
tales en plantas siderúrgicas en Brasil y México; además produce alambrón y láminas de acero en Indonesia, Malasia y México.

Las empresas petroleras y mineras chinas corresponden a casos de internacionalización más recientes. Petrochina extrae petróleo y gas en 30 países, entre ellos Brasil, Indonesia y Perú. Es subsidiaria de China National Petroleum Corporation, conglomerado con empresas en varios eslabones de la cadena de petróleo, desde la instalación de pozos hasta la comercialización del combustible al por menor. MMG extrae minerales en Australia, RD Congo, Laos y Perú, pero es subsidiaria de China Minmetals, conglomerado a quien abastece, y que tiene como subsidiarias desde siderurgias hasta empresas en el sector inmobiliario. Así, las CGV formadas por ambos conglomerados absorbe del mundo la materia prima necesaria para hacer posible el proceso acelerado de industrialización y urbanización implementado en China en los años 2000.

\section{CONCLUSIONES}

Mientras que, de acuerdo con el coeficiente de Leontief, la fabricación de automóviles es la actividad con mayor capacidad teórica de arrastre, el índice de cercanía muestra que es la construcción la que tiene más enlaces directos e indirectos con el resto de las industrias a nivel mundial. Es el crecimiento en ambos sectores, entre 1995 y 2011, el que ha movilizado a industrias intermediarias, como la refinación de petróleo, la manufactura química, la de metales básicos y la de productos metálicos, en específico de China, Corea, Estados Unidos de América, India y Japón, para que absorban los recursos mineros del planeta.

Entre los países aún en desarrollo evaluados, los grandes abastecedores mundiales de recursos mineros, en orden de valor de ventas son: Arabia Saudita, Indonesia, Brasil, México, Sudáfrica, Colombia, Malasia, Perú, Chile y Brunéi. No obstante, de acuerdo con el índice de cercanía del sector extractivo de cada uno, aquellos que tienen un alcance reducido de sus encadenamientos hacia atrás son: Colombia, Perú, Chile y Brunéi, por lo tanto, el efecto contagio de su crecimiento es restringido.

En cuanto al encadenamiento hacia adelante, la evaluación del valor agregado muestra un escalamiento industrial en la industria química de Brunéi, la manufactura de metales básicos de Indonesia y la refinación de petróleo y manufactura de productos metálicos de Malasia, pues han logrado avanzar a eslabones más sofisticados en las cadenas que usan recursos mineros. En el caso de las economías latinoamericanas, los resultados indican que, con excep- 
ción de México, han fortalecido su posición en las etapas iniciales de las CGV. En el caso mexicano, el efecto industrializador del escalamiento en los sectores de transformación de metales es limitado por la reducción relativa del valor agregado generado dentro del país.

La contribución del escalamiento en la industrialización se hace visible en Malasia e Indonesia, cuando se calcula la participación del valor agregado de la manufactura en el PIB. Esta participación aumentó 4\% en ambos casos, desde inicios de los años noventa hasta 2008; simultáneamente, en Colombia y Chile cayó 4 y 2\%, respectivamente. Para Brunéi, México y Perú, la reducción es más leve (UNIDO, 2019). Después de la crisis de 2008, la manufactura perdió peso en el pib en todos los países. Si bien, el efecto de la industrialización en el desarrollo económico no es automático, ya que depende de políticas redistributivas de cada país, los datos del Índice de Desarrollo Humano muestran una mejora anual del 1.14 y $0.91 \%$ para Indonesia y Malasia, respectivamente, porcentaje superior al resto de países, salvo Colombia, que ostenta un $0.97 \%$.

Entre las transnacionales evaluadas, las que lideran CGV, en el sentido estricto de la definición, son las empresas petroleras, pues gestionan desde la extracción del hidrocarburo hasta la venta de combustible al consumidor final en estaciones de servicio. Asimismo, parecido es el caso de Mitsubishi, que tiene a su cargo empresas que participan en la extracción de minerales y llegan hasta la venta de vehículos a través de establecimientos concesionarios.

Los casos de escalamiento industrial en los que participan las transnacionales evaluadas corresponden a movimientos hacia adelante a lo largo de las cadenas de valor y no a movimientos hacia atrás. Esto se presenta así porque, por lo general, las empresas extractoras realizan grandes compras de maquinaria, equipos e insumos en los mercados mundiales, limitando con ello su contribución a la creación local de industrias en los sectores correspondientes. Caso contrario, es más frecuente que una empresa de hidrocarburos añada a la extracción la actividad de la refinación de petróleo o licuefacción del gas o que una minera añada la refinación del metal. Esto debería ser considerado para el diseño de políticas industriales.

Existen importantes diferencias entre las multinacionales evaluadas de origen anglosajón y las de origen asiático. Estas últimas forman redes intersectoriales más integradas tanto vertical como horizontalmente, siendo Mitsubishi y los conglomerados chinos los casos más ramificados, pues utilizan en mayor medida el control propietario a lo largo de los eslabones de la cadena para garantizar el flujo del recurso natural desde su estado de materia prima hasta el bien o servicio final que ofrecen, sean gasolinas o viviendas. No obstante, 
el efecto industrializador de estas empresas en las economías en desarrollo depende del grado de internacionalización de su propia cadena productiva. Mientras que las transnacionales japonesas y coreanas tratan de internacionalizar etapas más avanzadas del procesamiento de los minerales e hidrocarburos, las empresas chinas han tratado de abastecerse de materias primas para hacer posible su propio proceso de industrialización.

\section{BIBLIOGRAFÍA}

Baldwin, R. y Lopez-Gonzales, J. (2013), Supply-chain trade: a portrait of global patterns and several testable hypotheses, Cambridge, National Bureau of Economic Research.

Bastian, M., Heymann, S. y Jacomy, M. (2009), “Gephi: an open source software for exploring and manipulating networks", International AAAI Conference on Weblogs and Social Media. Recuperado de <https://gephi.org/>

Blyde, J. (2014), Synchronized factories. Latin America and the Caribbean in the era of global value chains, Washington DC, Inter-American Development Bank.

Borgatti, S. y Everett, M. (2006), "A graph-theoretic perspective on centrality”, Social Networks, vol. 28, núm. 4, DOI <https://doi.org/10.1016/j. socnet.2005.11.005>

Brunei Embassy Washington DC (2018), Brunei Vision 2035 -Wawasan 2035. Recuperado de <http://www.bruneiembassy.org/brunei-vision-20 35.html>

Carney, M. (2005), "Globalization and the renewal of Asian business networks", Asia Pacific Journal of Management, vol. 22, núm. 4, DOI <https:// doi.org/10.1007/s10490-005-4114-z>

Chai, L., Liu, X., Zhang, J. y Baber, Z. (2011), "Application of social network theory to prioritizing oil \& gas industries protection in a networked critical infrastructure system", Journal of Loss Prevention in the Process Industries, vol. 24, núm. 5, DOI <https://doi.org/10.1016/j.jlp.2011.05.011>

Chenery, H. B., y Watanabe, T. (1958), "International comparisons of the structure of production", Econometrica, vol. 26, núm. 4, DOI $<10.2307 / 1907514>$

Comité Europeo de la Cooperación de las Industrias de la Máquina Herramienta (Сесімо) (2011), Study on competitiveness of the european machine tool industry, Brussels, CECIMO. 
Corden, M. y Neary, P. (1982), "Booming sector and de-indsutrialisation in a small open economy”, The Economic Journal, vol. 92, núm. 368, DOI <https://doi.org/10.2307/2232670>

Dussel, E. (2018), "Cadenas globales de valor. Metodología, contenidos e implicaciones para el caso de la atracción de inversión extranjera directa desde una perspectiva regional", en E. Dussel (coord.), Cadenas globales de valor. Metodología, teoría y debates, México, unam.

Freeman, L. (1979), "Centrality in social networks. Conceptual clarification", Social Networks, vol. 1, núm. 3, DOI <http://dx.doi.org/10.1016/03788733(78)90021-7>

García, A., Morillas, A. y Ramos, C. (2008), "Key sectors: a new proposal from network theory", Regional Studies, vol. 42, núm. 7, DOI <https://doi. org/10.1080/00343400701654152>

Gereffi, G. y Lee, J. (2016), "Economic and social upgrading in global value chains and industrial clusters: why governance matters", Journal of Business Ethics, vol. 133, núm. 1. Disponible en <https://papers.ssrn.com/sol3/ papers.cfm?abstract_id $=2721292>$

, Humphrey, J. y Sturgeon, T. (2005), "The governance of global value chains", Review of International Political Economy, vol. 12, núm.1, febrero, DOI <https://doi.org/10.1080/09692290500049805>

Hausmann, R. y Klinger, B. (2006), Structural transformation and patterns of comparative advantage in the product space, Cambridge, Center for International Development, Harvard University.

, Hwang, J. y Rodrik, D. (2007), "What you export matters", Journal of Economic Growth, vol. 12, núm. 1, DOI <https:/doi.org/10.1007/ s10887-006-9009-4>

Hidalgo, C. y Hausmann, R. (2009), "The building blocks of economic complexity", Proceedings of the national academy of sciences, vol. 106, núm. 26, DOI <https://doi.org/10.1073/pnas.0900943106>

Hirschman, A. (1964), La estrategia de desarrollo económico, 2a. edición, México, Fondo de Cultura Económica.

Kuznets, S. (1974), Crecimiento económico y estructura económica, 2a. edición, Barcelona, Editorial Ariel S. A.

Leontief, W. (1966), Input-Output Economics, New York, Oxford University Press on Demand.

López, J. (2014), "Encadenamientos productivos en el sureste de Asia: integración a las redes globales con empresas locales", Mundo Asia Pacífico, vol. 3, núm. 5, DOI <https://doi.org/10.17230/map.v3.i5.02> 
Los, B., Timmer, P. y De Vries, J. (2015), "How global are global value chains? A new approach to measure international fragmentation", Journal of Regional Science, vol. 55, núm. 1, DOI <https://doi.org/10.1111/jors.12121>

Ministry of International Trade and Industry (мІтI) (2018), Third Industrial Master Plan. Recuperado de <http://www.miti.gov.my/index.php/pages/ view/1690>

Ministry of National Development Planning (2018), Development Plan and Government Work Plan. Recuperado de <https://www.bappenas.go.id/index.php?cID=11314>

Noguera-Méndez, P., Semitiel-García, M. y López-Martínez, M. (2016), “Estructura interindustrial y desarrollo económico. Un análisis desde las perspectivas de redes e input-output", El Trimestre Económico, vol. LXXXIII (3), núm. 331, DOI <http://dx.doi.org/10.20430/ete.v83i331.212>

Organización para la Cooperación y el Desarrollo Económicos (OECD) (2016), Inter-Country Input-Output (ICIO) Tables, 2016 edition. Recuperado de $<$ http://www.oecd.org/sti/ind/inter-country-input-output-tables.htm>

Pérez, L. (2017), "Implicaciones de la segmentación internacional de la producción en términos de la capacidad de generar valor agregado y la dependencia de insumos importados en las manufacturas en México y en China”, en E. Dussel Peters (ccord.), América Latina y el Caribe y China. Economía, comercio e inversión 2017, Ciudad de México, Unión de Universidades de América Latina y el Caribe.

Ramírez, J. (2017), "Avatares de la estrategia industrial asiática”, en A. Girón y E. Correa (coords.), Reorganización financiera en Asia y América Latina en el periodo de postcrisis, Ciudad de México, unam.

Rasmussen, P. (1956), Relaciones intersectoriales, Madrid, Aguilar.

Rodil, Ó. (2017), "Las relaciones intersectoriales de América Latina con China en el marco de las cadenas globales de valor", en E. Dussel Peters (coord.), América Latina y el Caribe y China. Economía, comercio e inversión 2017, Ciudad de México, Unión de Universidades de América Latina y el Caribe.

Rodrik, D. (2011), Una economía, muchas recetas: la globalización, las instituciones y el crecimiento económico, México, Fondo de Cultura Económica.

Sachs, J. y Warner, A. (2001), "The curse of natural resources", European Economic Review, 45, DOI <https://doi.org/10.1016/S0014-2921(01)00 $125-8>$

Schuschny, R. (2005), Tópicos sobre el Modelo de Insumo-Producto: teoría y aplicaciones, Santiago de Chile, CePAL. 
Yuri Landa Arroyo

Timmer, M., Erumban, A., Los, L., Stehrer, R. y de Vries, G. (2014), "Slicing up global value chains", Journal of Economic Perspectives, vol. 28, núm. 2, DOI <http://doi.org/10.1257/jep.28.2.99>

United Nations Industrial Development Organization (UnIDo) (2019), Statistics Data Portal. MVA 2019, Manufacturing. Recuperado de <https:// www.unido.org/researchers/statistical-databases>

Wilson, J. (2014), "Northeast Asian Resource Security Strategies and International Resource Politics in Asia”, Asian Studies Review, vol. 38, núm. 1, DOI <https://doi.org/10.1080/10357823.2013.853027>

World Bank (2018), World Development Indicators, Washington D.C., World Bank. 